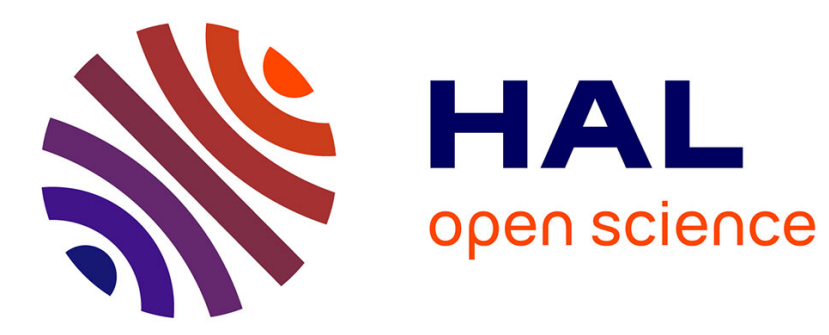

\title{
Resource Saving: Which Resource Sharing Strategy to Protect Primary Shortest Paths?
}

Mohand-Yazid Saidi, Bernard Cousin

\section{To cite this version:}

Mohand-Yazid Saidi, Bernard Cousin. Resource Saving: Which Resource Sharing Strategy to Protect Primary Shortest Paths?. IEEE Consumer Communications and Networking Conference (CCNC), Jan 2016, Las Vegas, United States. 10.1109/CCNC.2016.7444788 . hal-01305742v2

HAL Id: hal-01305742

https://hal.science/hal-01305742v2

Submitted on 11 May 2017

HAL is a multi-disciplinary open access archive for the deposit and dissemination of scientific research documents, whether they are published or not. The documents may come from teaching and research institutions in France or abroad, or from public or private research centers.
L'archive ouverte pluridisciplinaire HAL, est destinée au dépôt et à la diffusion de documents scientifiques de niveau recherche, publiés ou non, émanant des établissements d'enseignement et de recherche français ou étrangers, des laboratoires publics ou privés. 


\section{Resource Saving: Which Resource Sharing Strategy to Protect Primary Shortest Paths?}

\author{
Mohand-Yazid SAIDI \\ L2TI / Institut Galilée \\ Université Paris 13 Sorbonne Paris Cité \\ 99 Avenue Jean Baptiste Clément, 93430 Villetaneuse, France \\ Email: saidi@univ-paris13.fr
}

\author{
Bernard COUSIN \\ IRISA \\ Université de Rennes I \\ France \\ Email: bcousin@irisa.fr
}

\begin{abstract}
Two strategies of resource sharing are proposed in literature to provide protection while saving resources: (1) restrained sharing which applies the resource sharing to the backup paths only and (2) global sharing which extends the resource sharing to the primary and backup paths.

In this paper, we compared the two strategies of resource sharing when the primary paths correspond to the shortest ones according to a strictly positive and static metric. Even when the amount of resources that can be shared between the primary and the backup paths is unbounded, we proved that the maximum number of backup paths is still bounded. Besides, our simulations showed that the resource sharing between the primary and backup paths has very slight impact on the backup path rejection, i.e. the two strategies of resource sharing have very close performances.
\end{abstract}

\section{INTRODUCTION}

To save the resources ${ }^{1}$, most of routing protocols (OSPF, RIP, etc.) use the shortest paths for traffic transport. Moreover, to ensure service continuity even after failures, the primary (shortest) paths should be protected by pre-computing and generally configuring backup paths. Upon a failure occurrence, only backup paths protecting against that failure are activated to repair the affected primary paths. As a result, the backup paths protecting against different failures should share their resources to save them [1]. Such a sharing, applied only between backup paths, is called in this paper restrained resource sharing (RRS).

To improve the resource allocations, Balon and al. [2] propose to extend the resource sharing by applying it between the primary and backup paths. In fact, a failure repair results in the bypass of some parts of primary paths. Thus, links belonging to the bypassed primary parts free up resources that can be reallocated to the backup paths which protect against that failure. The resource sharing between the backup paths and between the backup-primary paths is called here global resource sharing (GRS).

Although the primary paths often correspond to the shortest ones, in our knowledge there is no work studying the impact of such primary routing decision on the rejection rate of paths. In this paper, we try to fill the gap by studying and measuring the impact of an optimal primary routing, according to a strictly positive and static metric, on the performances of the backup

\footnotetext{
${ }^{1}$ In the rest of this document, resource refers to bandwidth.
}

path routing. The rest of this paper is organized as follows. The control admission models used by the two strategies of resource sharing are presented in Section II. In Section III, we study formally the impact of resource sharing strategies on the number of backup paths. In Section IV, we compare and measure by simulations the gain obtained by the use of GRS instead of RRS. Section V is dedicated to the conclusions.

\section{ADMISSION CONTROL FOR BACKUP PATHS}

To save resources and accept more path establishment requests, resources should be shared between paths. With the assumption of single failures, only backup paths protecting against the same failure could be activated at the same time. Let us define the protection costs $\delta_{r}^{\lambda}$ of failure risk $r$ (link or node) on the link $\lambda$ as the cumulative bandwidth of backup paths that should be activated to recover from failure $r$. With RRS, we determine the protection bandwidth $R^{\lambda}$ that should be reserved for protection on link $\lambda$ as follows:

$$
R^{\lambda}=\max _{r} \delta_{r}^{\lambda}
$$

The total bandwidth $b w(\lambda)$ allocated on $\lambda$ must be always smaller than the capacity $C^{\lambda}$ of link $\lambda$ :

$$
b w(\lambda)=P^{\lambda}+R^{\lambda}=P^{\lambda}+\max _{r} \delta_{r}^{\lambda} \leq C^{\lambda}
$$

where $P^{\lambda}$ is the cumulative bandwidth of the primary paths crossing link $\lambda$.

By defining $L_{r}^{\lambda}$ as the freed bandwidth on primary link $\lambda$ upon failure $r$, we determine with GRS the amount of bandwidth $R^{\lambda}$ that should be reserved for backup paths as follows:

$$
R^{\lambda}=\max _{r}\left(\delta_{r}^{\lambda}-L_{r}^{\lambda}, 0\right)
$$

The bandwidth $b w(\lambda)$ allocated on $\lambda$ corresponds to:

$$
b w(\lambda)=P^{\lambda}+R^{\lambda}=P^{\lambda}+\max _{r}\left(\delta_{r}^{\lambda}-L_{r}^{\lambda}, 0\right) \leq C^{\lambda}
$$

III. IMPACT OF THE AMOUNT OF THE FREED BANDWIDTH ON THE MAXIMUM NUMBER OF BACKUP PATHS

Although it seems that GRS is more efficient than RRS, we show in the rest of this paper that the two strategies have close performances when the primary paths correspond to the shortest ones. 


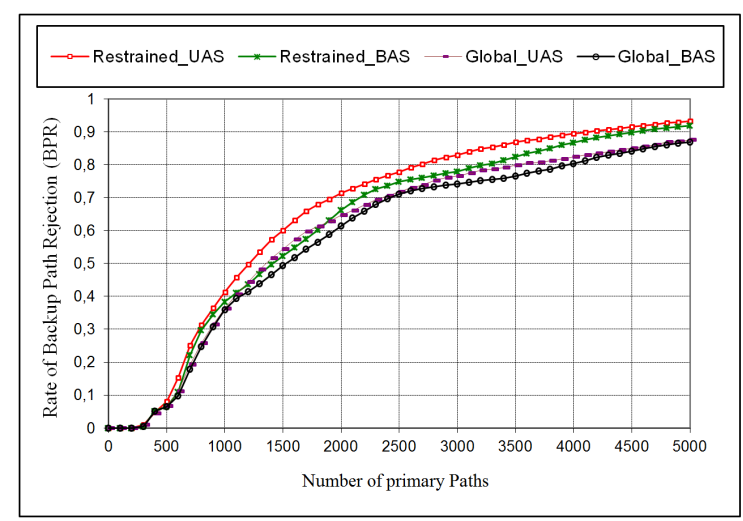

(a) Long Haul

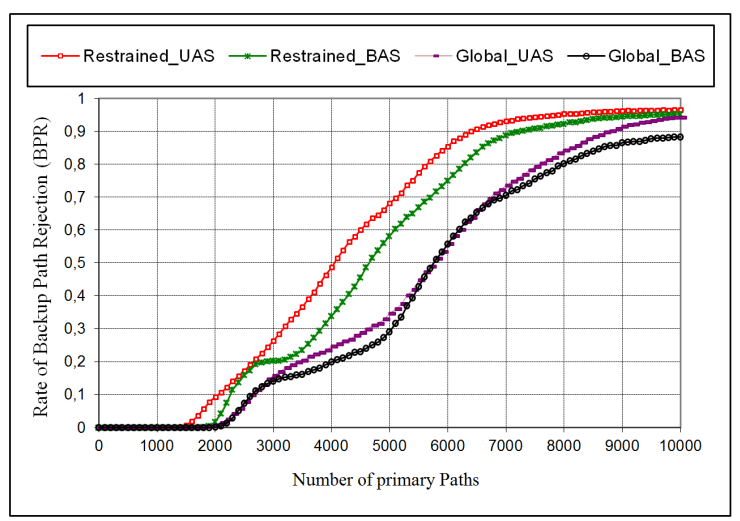

(b) Cost 239

Fig. 1: Evolution of the mean rate of backup path rejection

Theorem 3.1: Consider GRS and RRS, and assume that any path requires at least one unit of bandwidth. The number of backup paths protecting shortest primary paths is bounded if the capacities of links are bounded.

Proof: Due to the lack of space, we present here only the idea of the proof. (1) Without the exploitation of the freed primary bandwidth (i.e. with RRS), it is obvious that the number of backup paths is bounded. (2) With the use of the freed bandwidth (i.e. with GRS), we show that the number of backup paths protecting against the failure of risk $r$ is bounded by proving that any backup path should traverse at least one link $\lambda$ that cannot free up bandwidth upon failure $r$.

For both GRS ans RRS, we proved in this section that the number of backup paths is bounded even if the freed bandwidth on links is unbounded.

\section{Simulation and Performance Analysis}

In order to quantify the gain in performances due to the use of GRS instead of RRS, we compared the two resource sharing strategies by simulations. In our experiments, we used two well known topologies of network: USA Long Haul and Cost 239. All the protection capacities of links are equal to 200 units in each direction except for 6 links located on the northeast border of Long Haul network which have a protection capacity of 600 units. In our tests, we considered two scenarios: unidirectional allocation-based scenario $(U A S)$ and bidirectional allocationbased scenario $(B A S)$.

We generated sequentially 1000 demands of path protection asking for bandwidth quantities uniformly distributed between 1 and 10 units. Each demand is composed of one primary path establishment request that is assumed to be always satisfied and several requests of backup path establishment to protect locally the primary path. We applied the shortest path first (SPF) algorithm for the primary path computation and we used the constrained shortest path first (CSPF) algorithm for the computation of backup paths.

Figure 1 shows the evolution of the instantaneous rate of backup path rejection $(B P R)$ as a function of the number of primary paths setup in the network. We note that the comparison criterion corresponds to the ratio of backup paths that are rejected because of the lack of protection bandwidth on the network links and the number of protection requests. It is computed for different network loads.

As expected, the difference in performances between GRS and RRS is almost imperceptible for low traffic loads where the rejection rate of backup paths is small and usual. For high traffic loads where the rejection rate of backup paths is high, GRS is slightly better than RRS. Thus, our simulations comfort our theoretical results (see Therem 3.1) and show clearly that the number of backup paths is always bounded even if the freed bandwidth is unbounded on the links that are capable to free up bandwidth.

\section{CONCLUSiON}

In this article, we presented two known strategies of resource sharing: restrained resource sharing and global resource sharing. The first strategy limits the resource sharing to the backup paths that protect against different failure risks whereas the second strategy extends the resource sharing to the primary and backup paths that could not receive traffic at the same time.

To measure the gain obtained by the extension of the resource sharing to primary and backup paths, we firstly showed theoretically that the resource sharing between the primary and backup paths is limited to some links which cannot form a backup path. Thus, the maximum number of backup paths is bounded regardless of the resource sharing strategy that is applied. Secondly, to quantify the improvement due to the resource sharing between the primary and backup paths, we showed by simulations that the gain in performances is often imperceptible, particularly for low traffic loads. As a result, we affirm that the global resource sharing strategy cannot be a long term solution for supporting bandwidthintensive applications especially since it induces an overcost.

\section{REFERENCES}

[1] M. Y. Hariyawan, "Comparison Analysis of Recovery Mechanism at MPLS Network," International Journal of Electrical and Computer Engineering (IJECE), vol. 1, no. 2, pp. 151-160, 2011.

[2] S. Balon, L. Mélon, and G. Leduc, "A Scalable and Decentralized Fast-Rerouting Scheme with Efficient Bandwidth Sharing," Computer Networks, vol. 50, no. 16, pp. 3043-3063, November 2006. 